Article

\title{
Systematic and Model-Assisted Evaluation of Solvent Based- or Pressurized Hot Water Extraction for the Extraction of Artemisinin from Artemisia annua L.
}

\author{
Maximilian Sixt and Jochen Strube* \\ Institute for Separation and Process Technology, Clausthal University of Technology, 38678 Clausthal-Zellerfeld, \\ Germany; sixt@itv.tu-clausthal.de \\ * Correspondence: strube@itv.tu-clausthal.de
}

Received: 24 November 2017; Accepted: 15 December 2017; Published: 20 December 2017

\begin{abstract}
In this study, the solvent based extraction of artemisinin from Artemisia annua L. using acetone in percolation mode is compared to the method of pressurized hot water extraction. Both techniques are simulated by a physico-chemical process model. The model as well as the model parameter determination, including the thermal degradation of artemisinin are shown and discussed. For the conventional extraction, a solvent screening is performed considering various organic solvents. A temperature screening is presented for the systematic design of the pressurized hot water extraction. The best temperature with regards to thermal decomposition and high productivity was found to be $80^{\circ} \mathrm{C}$. Both, conventional percolation and Pressurized Hot Water Extraction (PHWE) are suitable for the extraction of artemisinin. The extraction curves show a high conformity with the simulation results.
\end{abstract}

Keywords: artemisinin; extraction; modeling; simulation; Green Solvents; Pressurized Hot Water Extraction

\section{Introduction}

The demand for natural derived products is still growing [1,2]. Among other purposes, they are used as food supplements, natural plant protection agents and pharmaceuticals. The field of phyto pharmaceuticals can roughly be divided into extract types and pure substances. Extract types are often applied for self-medication and to cure e.g., common colds or stomach trouble. The whole process usually consists of extraction, evaporation for solvent recycling, drying and formulation. No additional purification steps are needed or rather wanted and the whole complex extract is used. The pure substances instead are often highly effective active pharmaceutical ingredients that have to be prescribed and dosed by a physician. One example is the anti-cancer drug Paclitaxe ${ }^{\circledR}$ which is produced by semi-synthesis from the precursor 10-deacetylbaccatin III, that is found in the needles of European yew (Taxus baccata L.). Another substance is the anti-malaria agent artemisinin from annual mugwort (Artemisia annua L.). These substances are extracted from the plant matrix and afterwards purified to pharma grade, typically by liquid-liquid extraction, chromatography, and a final crystallization [3-6]. They are commonly applied as a pure substance and the whole complexity of the crude plant extract is neither desired nor is it approved. In that case, the solid liquid extraction process should aim for maximized yield of the active substance. Extract purity is not that significant because of the downstream processing, which is needed anyway, and that has to be tailor-made for that specific product.

In this study, the systematic process design for extraction of artemisinin from mugwort is shown. A solvent-based percolation, as it is state of the art in industry, is assessed to the so called Pressurized Hot Water Extraction (PHWE). This specific method provides an alternative process design to avoid 
organic solvents. It is therefore well-suited for the extraction of natural products under kosher and halal constraints. Moreover, it showed high productivity for the extraction of an active pharmaceutical ingredient in a previous study [7], has a wide range of applications [8,9], and commercial equipment is available [10,11].

Annual mugwort (Artemisia annua L.) is an up to $2 \mathrm{~m}$ high annual plant, growing mainly in the moderate climatic zone. It belongs to the plant family of Asteraceae. The main active ingredient is artemisinin with a content ranging from $0.01 \mathrm{wt} \%$ to $1.5 \mathrm{wt} \%$ [12]. Artemisinin shows a high efficacy against parasites of the species plasmodium that are responsible for malaria disease [13,14]. According to literature, artemisinin is located in the leaves and flowers but not in the stem and the roots of mugwort [15]. Because artemisinin is toxic for the plant cells, it is located on the surface of the leaves in glandular trichomes. There, it serves as a natural protection against predators, fungi and other pathogens [16].

The sesquiterpene lactone artemisinin was first isolated by Tu Youyou, a Chinese scientist, who was awarded half of the 2015 Nobel Prize in Medicine for her discovery [17]. The characteristic of the molecule, which is shown in Figure 1, is the peroxide bridge which is believed to be responsible for the drug's mechanism of action [18].

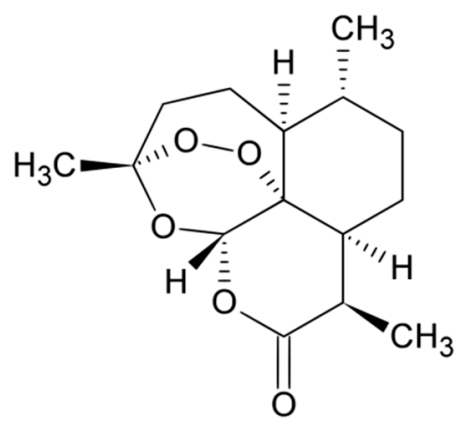

Figure 1. Structure of artemisinin.

There is a great variety of methods for the extraction of artemisinin from mugwort. In the following, a rough summary is given to illustrate the topic to the reader: In an already patented approach by Kumar et al., dry leaves are extracted with non-aqueous solvents such as ethanol, methanol, acetone, methylisobutyl, and hexane [19]. Besides rather traditional techniques, artemisinin is an often chosen model system for new extraction processes and mass transport enhancing methods. Hao et al. describe the microwave-assisted extraction using different solvents such as ethanol, trichloromethane, and cyclohexane. The best results were obtained using $n$-hexane, microwave radiation for $12 \mathrm{~min}$ and a solvent ratio of 11.3 (solvent/plant material). Moreover, they observed the best results when the plant material is ground to less than $0.125 \mathrm{~mm}$. They compared their results to extraction using supercritical carbon dioxide, Soxhlet method, and maceration and concluded that their method gives the highest extraction rates [20]. Briars et al. investigated the ultrasound-assisted extraction. They compared maceration and ultrasound-assisted maceration at three different temperature levels $\left(25^{\circ} \mathrm{C}, 35^{\circ} \mathrm{C}\right.$, and $\left.45^{\circ} \mathrm{C}\right)$. They showed that the highest selectivity towards artemisinin is reached with US-assisted extraction using hexane at $25^{\circ} \mathrm{C}$ thus saving energy costs [21]. Another approach is demonstrated by Quispe-Condori et al. [22], and Kohler et al. [23]. Both groups extracted artemisinin successfully with supercritical carbon dioxide. Kohler et al. observed that the extraction can be optimized by applying flow rates of $2 \mathrm{~mL} / \mathrm{min}$ for $20 \mathrm{~min}$. The fluid consisted of carbon dioxide and $3 \%$ of methanol at $50{ }^{\circ} \mathrm{C}$ and 150 bar. By analyzing the shape of the extraction curves, they concluded, that the extraction is not limited by diffusion but by the elution process [23]. Quispe-Condori et al. performed a complete factorial design to optimize the extraction. Their two best yields were obtained using pure carbon dioxide at $30{ }^{\circ} \mathrm{C}$ and 150 bar, and $50{ }^{\circ} \mathrm{C}$ and 300 bar. They compared their data with the extraction models by Sovová [24] and Martinez [25] 
and found a good agreement [22]. Lapkin et al. did an explanatory summary of different methods and solvents for extracting artemisinin, such as ionic liquids or the hydrofluorocarbon HFC-134a. They showed that using HFC-134a or ionic liquids leads to a higher extraction efficiency compared to conventional solvents such as hexane. They also indicated that for the HFC-134a solvent an extraction equipment is already commercially available [26]. Christen et al. reported the pressurized solvent extraction or accelerated solvent extraction. $100 \mathrm{mg}$ of mugwort powder were extracted with ethanol and water in a temperature range from $25{ }^{\circ} \mathrm{C}$ to $100{ }^{\circ} \mathrm{C}$ under reflux. They observed increasing yield at elevated temperature and concluded that there must be a limitation due to solubility at room temperature [12].

In this study, conventional percolation and the so called Pressurized Hot Water Extraction (PHWE) are investigated. In both methods, fresh solvent is pumped through a column filled with plant material. By that, a concentration gradient is maintained between the solvent and the plant material, therefore a complete leaching is possible. In PHWE, the enhanced solubility of active pharmaceutical ingredients relies on the changing polarity of water with rising temperature. This is expressed by the dielectric constant $\varepsilon$. Under ambient conditions $\varepsilon$ of water has a value of roughly 80 , decreasing to 34.8 at $200{ }^{\circ} \mathrm{C}$, thus being close to the value of methanol $(32.7)$ at ambient conditions $[8,27]$. The corresponding dielectric constant of various organic solvents under normal conditions and the data for water are given in Figure 2.

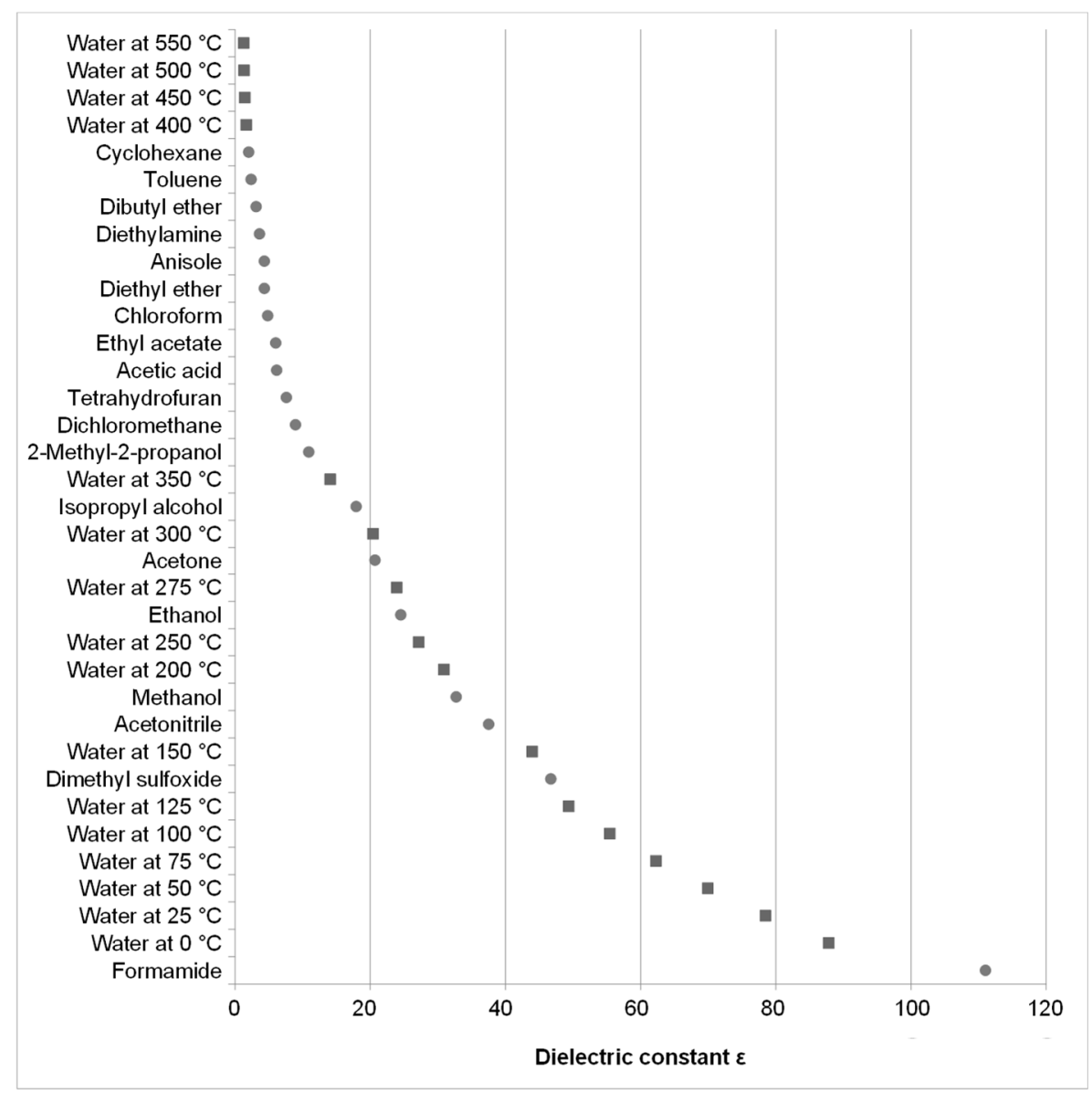

Figure 2. Dielectric constant chart, values from [27] and Equation (1).

The dielectric constant of water can be calculated by Equation (1) [28].

$$
\varepsilon=1+\left(\frac{\mathrm{A}}{\mathrm{T}^{*}}\right) \varrho^{*}+\left(\frac{\mathrm{B}}{\mathrm{T}^{*}}+\mathrm{C}+\mathrm{DT}^{*}\right) \varrho^{* 2}+\left(\frac{\mathrm{E}}{\mathrm{T}^{*}}+\mathrm{FT}^{*}+\mathrm{GT}^{* 2}\right) \varrho^{* 3}+\left(\frac{\mathrm{H}}{\mathrm{T}^{* 2}}+\frac{\mathrm{I}}{\mathrm{T}^{*}}+\mathrm{K}\right) \varrho^{* 4}
$$




$$
\begin{gathered}
\mathrm{T}^{*}=\frac{\mathrm{T}}{298.15 \mathrm{~K}}, \varrho^{*}=\frac{\varrho}{1000 \mathrm{~kg} / \mathrm{m}^{3}}, \mathrm{~A}=+7.62571, \mathrm{~B}=+244.003, \mathrm{C}=-140.569, \mathrm{D}=+27.7841, \\
\mathrm{E}=-96.2805, \mathrm{~F}=+41.7907, \mathrm{G}=-10.2099, \mathrm{H}=-45.2059, \mathrm{I}=+84.6395, \mathrm{~K}=-35.8644 .
\end{gathered}
$$

Besides the dielectric constant, some other parameters are affected by temperature increase. For example the $\mathrm{pH}$, which is 7 at normal conditions, changes to a value of 5.5 at $250{ }^{\circ} \mathrm{C}$. Some other highly temperature-sensitive parameters are the surface tension, self-diffusivity and viscosity [8].

\section{Material and Methods}

\subsection{Raw Material}

Raw Artemisia anпua L. was ordered from CfM Oskar Tropitzsch (Markredwitz, Germany). The herb was ground to approximately $1 \mathrm{~mm}$ prior to extraction in a knife mill $\operatorname{Retsch}^{\circledR}$ Grindomix ${ }^{\circledR} 200$, (Haan, Germany). The plant material was stored in the refrigerator at $-20{ }^{\circ} \mathrm{C}$ to minimize the decomposition of artemisinin.

\subsection{Solvent Screening}

Solvent screening was performed in $50 \mathrm{~mL}$ Falcons ${ }^{\circledR}\left(\mathrm{VWR}^{\circledR}\right.$, Darmstadt, Germany) using $3 \mathrm{~g}$ of ground plant material and $40 \mathrm{~mL}$ of solvent. The mixtures were agitated on a tilting table for $24 \mathrm{~h}$ before a sample was taken and analyzed. All solvents were in analytical grade.

\subsection{Conventional Extraction}

The conventional extraction is performed as multistep maceration for the equilibrium measurements and as percolation for the determination of the extraction kinetics as well as the overall amount. The maceration device is a stirred tank of approximately $1.5 \mathrm{~L}$. It is equipped with a stirrer, driven by a lab stirrer motor from IKA ${ }^{\circledR}$ to ensure proper mixing. A Teflon ${ }^{\circledR}$ seal prevents solvent from leaking through the gap between the top and the vessel. The device can be tempered. Percolation is performed in a stainless steel tube equipped with frits to ensure solid retention during extraction. A P110 preparative HPLC pump from VWR ${ }^{\circledR}$ as well as a Foxy Jr. fraction collector are used. Both are controlled by the EZChrom Elite ${ }^{\circledR}$ HPLC Software (Agilent, Santa Clara, CA, USA). The fractions serve for the determination of the extraction curve. The experimental setups have already been described by the authors [1,29].

\subsection{Pressurized Hot Water Extraction}

The flow diagram of the Pressurized Hot Water Extraction (PHWE) equipment for batch extraction experiments is shown in Figure 3. The water is pumped from a storage vessel by a HPLC pump P130 from $\mathrm{VWR}^{\circledR}$ to the extraction column filled with ground plant material. The extraction column is made from stainless steel with $10 \mathrm{~mm}$ i.d. $\times 100 \mathrm{~mm}$ (approx. $7.85 \mathrm{~mL}$ ). The column itself and a coil made of a steel capillary (length $=3 \mathrm{~m}$, i.d. $=1 \mathrm{~mm}$ ) are placed in a GC oven HP 5890 Series II Plus (Palo Alto, CA, USA) serving as heating device. The water is preheated in the coil before reaching the extraction column. The extract leaves the extraction column at the back-end where a filter frit serves for solid-liquid separation. The extract is transferred into a second coil for effective cooling (length $=3 \mathrm{~m}$, i.d. $=1 \mathrm{~mm}$ ). The pressure drop is adjusted by a valve to keep the water in liquid state. The flow sheet of the apparatus is given in Figure 3.

To determine the thermal degradation of the investigated components during extraction, the milli-scale device is modified to operate in recycling mode. This setup is shown in Figure 4. The extract is transferred into the storage vessel (max. $100 \mathrm{~mL}$ ) and is recycled during the whole process. Thus the target component accumulates in the system and occurring degradation effects can be studied. The storage vessel itself is located in an ultrasonic bath for mixing and avoiding possible agglomerates as well as concentration gradients inside the vessel. Both setups have already been introduced by the authors [7]. 


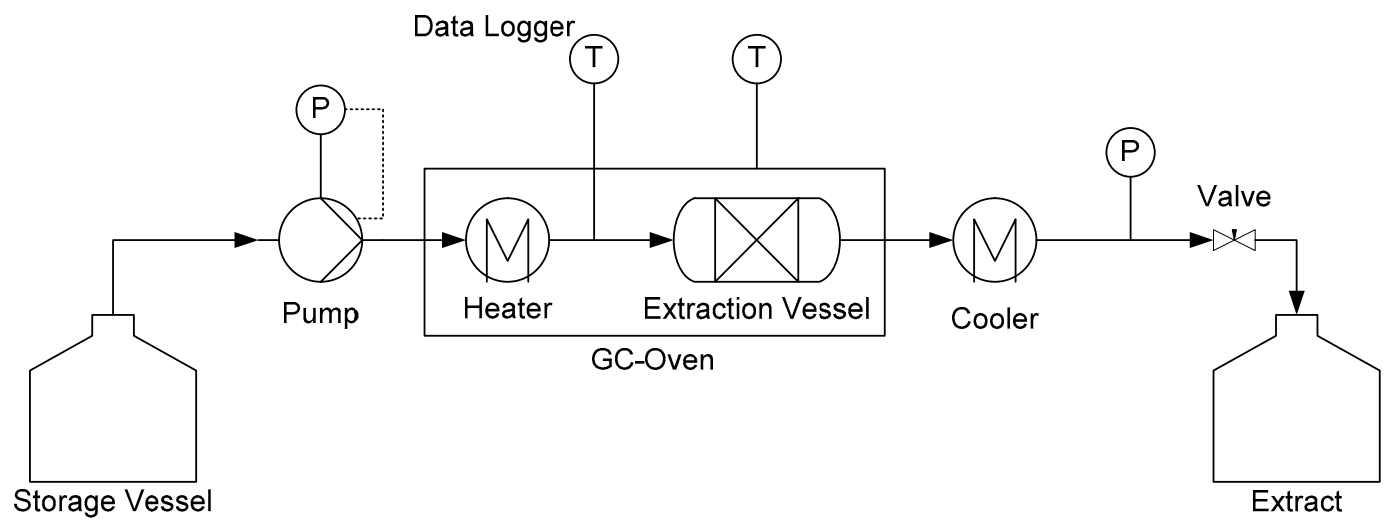

Figure 3. Flow diagram of the milli-scale Pressurized Hot Water Extraction (PHWE) equipment for batch extraction experiments.

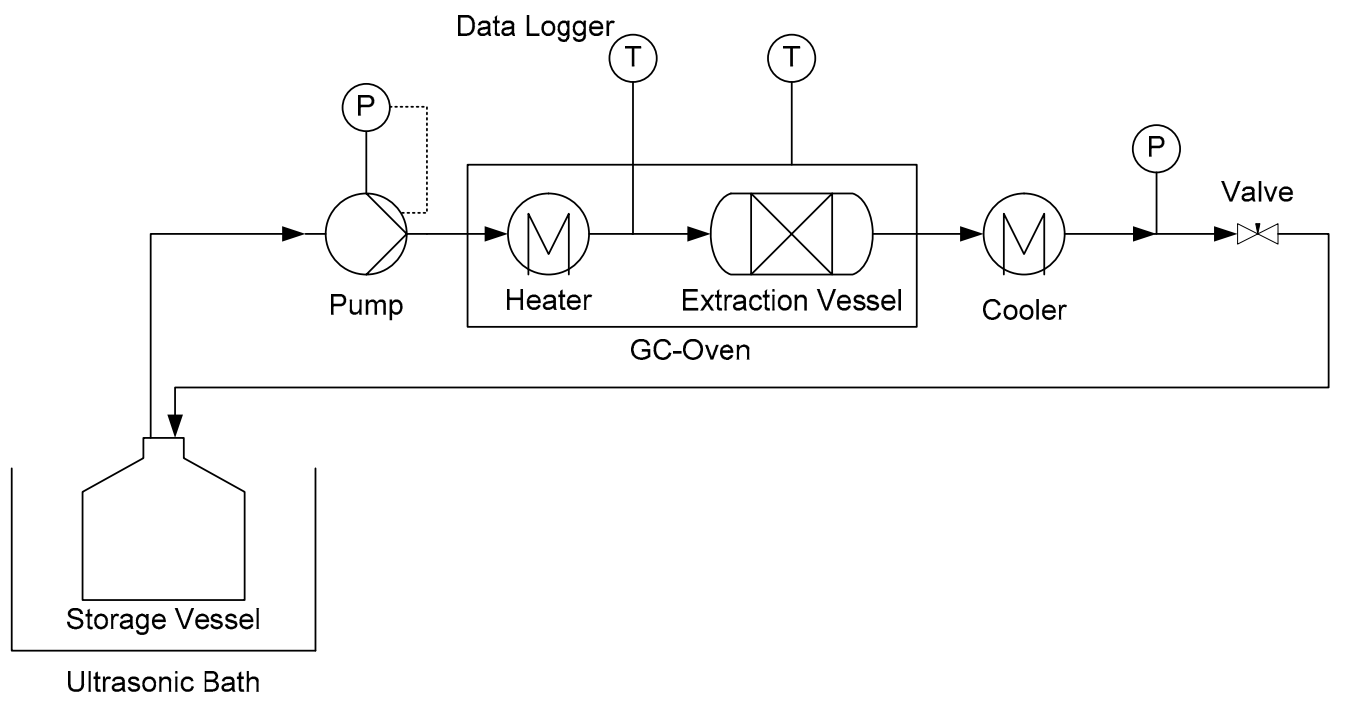

Figure 4. Flow diagram of the milli-scale PHWE equipment in recycling mode.

\subsection{Analytics}

The analysis of artemisinin is performed by HPLC using an Elite LaChrom ${ }^{\circledR}$ device equipped with an Evaporation Light Scattering Detector (ELSD) detector Alltech ${ }^{\circledR} 3300$ (Grace ${ }^{\circledR}$, Columbia, SC, USA). The analytical column is a PharmPrep RP18 $250 \mathrm{~mm} \times 4 \mathrm{~mm}$ i.d. by Merck ${ }^{\circledR}$ operated at $25^{\circ} \mathrm{C}$. The eluents are acetonitrile $\left(\mathrm{VWR}^{\circledR}\right.$, Darmstadt, Germany) and water (Sartorius ${ }^{\circledR}$ arium ${ }^{\circledR}$ pro, Göttingen, Germany) $60 / 40$ in isocratic mode at $1 \mathrm{~mL} / \mathrm{min}$ flow. The injection volume is $10 \mu \mathrm{L}$ and all samples are passed through a $0.2 \mu \mathrm{m}$ syringe filter. The evaporator temperature of the ELSD is set to $36{ }^{\circ} \mathrm{C}$ and the air flow is $1.6 \mathrm{~mL} / \mathrm{min}$. Calibration was performed with an external standard ordered from CfM Oskar Tropitzsch (Marktredwitz, Germany) over a range from $1 \mathrm{~g} / \mathrm{L}$ to $0.001 \mathrm{~g} / \mathrm{L}$. The basis of the HPLC analysis protocol can be found in Lapkin et al. [30]. It was slightly modified to fit the setup used in this study.

\section{Process Modeling}

For a competitive process design for plant based substances, maximum extraction yield is desirable. Thus, the most important extraction technique to achieve this aim is percolation. For process design and optimization, modeling and simulation was proven to be a beneficial approach $[1,3,4,7,29,31]$. Commonly, the extraction in percolation mode is described with various sub models which will be described in the following in detail. 
The macroscopic mass transport in the bulk phase (solvent) is described by the so called distributed plug flow (DPF) model.

$$
\frac{\partial c_{L}(z, t)}{\partial t}=D_{a x} \cdot \frac{\partial^{2} c_{L}(z, t)}{\partial z^{2}}-\frac{\mathbf{u}_{\mathbf{z}}}{\varepsilon} \cdot \frac{\partial c_{L}(z, t)}{\partial z}-\frac{1-\varepsilon}{\varepsilon} \cdot \mathbf{k}_{\mathbf{f}} \cdot \mathbf{a}_{\mathbf{P}} \cdot\left[c_{L}(z, t)-c_{P}(r=R, z, t)\right]
$$

The model parameters are printed in bold and the model parameter determination pathway is depicted in the following:

The axial dispersion coefficient $\mathbf{D}_{\mathrm{ax}}$ can be derived by deconvolution of tracer signals. An alternative method is applying correlations using the Péclet $(\mathrm{Pe})$ and the Reynolds (Re) number. Both ways are good engineering practice e.g., in chromatography [32-34].

$$
\mathrm{Pe}=\frac{0.2}{\varepsilon}+\frac{0.011}{\varepsilon}(\varepsilon \cdot \operatorname{Re})^{0.48}
$$

The Reynolds number expresses the ratio of the specific inertia and viscous forces. The formula symbols are: $u_{z}$ empty column velocity, $d_{P}$ mean particle diameter, $\varrho_{L}$ solvent density, $\eta$ solvent viscosity and $\varepsilon$ void fraction.

$$
\operatorname{Re}=\frac{\mathrm{u}_{\mathrm{z}} \cdot \mathrm{d}_{\mathrm{P}} \cdot \varrho_{\mathrm{L}}}{\eta \cdot \varepsilon}
$$

For the calculation of the Reynolds number the empty column velocity and the void fraction of the packed bed must be known. The empty column velocity is derived from the mass balance: $\dot{V}$ is the volumetric flux, $\mathrm{d}_{\mathrm{c}}$ the column diameter and $\mathrm{L}_{\mathrm{c}}$ the column length.

$$
\mathrm{u}_{\mathrm{z}}=\frac{\dot{\mathrm{V}}}{\mathrm{d}_{\mathrm{c}}^{2} \cdot \pi \cdot \mathrm{L}_{\mathrm{c}} \cdot 0.25}
$$

The void fraction can be measured with tracer experiments as well where the retention time of the non-binding tracer is $\mathrm{t}_{0}$.

$$
\varepsilon=\frac{\mathrm{t}_{0} \cdot \mathrm{u}_{\mathrm{z}}}{\mathrm{d}_{\mathrm{c}}^{2} \cdot \pi \cdot \mathrm{L}_{\mathrm{c}} \cdot 0.25}
$$

With that data and the Péclet number $\mathrm{D}_{\mathrm{ax}}$ can be calculated.

$$
\mathrm{D}_{\mathrm{ax}}=\frac{\mathrm{d}_{\mathrm{P}} \cdot \mathrm{u}_{\mathrm{z}}}{\varepsilon \cdot \mathrm{Pe}}
$$

The specific surface area $a_{\mathbf{P}}$ in case of spherical particles can be derived as:

$$
\mathrm{a}_{\mathrm{P}}=\frac{6}{\mathrm{~d}_{\mathrm{P}}}
$$

The mass transfer coefficient $\mathbf{k}_{\mathbf{f}}$ through the laminar boundary layer surrounding the particle is calculated with correlations using the Sherwood (Sh) and Schmitt (Sc) number. The binary diffusion coefficient $D_{12}$ has to be derived from measurements.

$$
\begin{gathered}
\mathrm{Sh}=\frac{\mathrm{k}_{\mathrm{f}} \cdot \mathrm{d}_{\mathrm{P}}}{\mathrm{D}_{12}} \\
\mathrm{Sc}=\frac{\eta}{\varrho_{\mathrm{L}} \cdot \mathrm{D}_{12}} \\
\mathrm{Sh}=2+1.1 \cdot \mathrm{Sc}^{0.33} \cdot \mathrm{Re}^{0.6}
\end{gathered}
$$

To take thermal degradation during extraction with hot solvents into account, the DPF-model is extended with a degradation kinetics (Equation (12)). The order and the rate constant of the reaction can be measured by recycling the extract continuously while taking samples in appropriate time intervals. 


$$
\frac{\partial c_{L}(z, t)}{\partial t}=D_{a x} \cdot \frac{\partial^{2} c_{L}(z, t)}{\partial z^{2}}-\frac{u_{z}}{\varepsilon} \cdot \frac{\partial c_{L}(z, t)}{\partial z}-\frac{1-\varepsilon}{\varepsilon} \cdot k_{f} \cdot a_{P} \cdot\left[c_{L}(z, t)-c_{P}(r=R, z, t)\right]-k_{\text {reac }} \cdot c_{L}(z, t)^{n}
$$

In the porous matrix of the plant material Equation (13) is derived from Fick's second law of diffusion. The effective diffusion coefficient must be determined by extraction experiments. The total loading of the plant material $\mathrm{q}$ with the specific target or side components can be measured by exhaustive percolation.

$$
\frac{\partial \mathrm{q}(\mathrm{z}, \mathrm{r}, \mathrm{t})}{\partial \mathrm{t}}=\mathrm{D}_{\text {eff }}(\mathrm{r}) \cdot\left(\frac{\partial^{2} \mathrm{c}_{\mathrm{P}}(\mathrm{z}, \mathrm{r})}{\partial \mathrm{r}^{2}}+\frac{2}{\mathrm{r}} \cdot \frac{\partial \mathrm{c}_{\mathrm{P}}(\mathrm{z}, \mathrm{r})}{\partial \mathrm{r}}\right)+\frac{\partial \mathrm{D}_{\text {eff }}(\mathrm{r})}{\partial \mathrm{r}} \cdot \frac{\partial c_{\mathrm{P}}(\mathrm{z}, \mathrm{r})}{\partial \mathrm{r}}
$$

The relation of target and side components located in the porous structure of the plant material $\mathrm{q}$ and dissolved in the extraction agent $c$ is rated by equilibrium curves such as Langmuir (14). For the parameter determination a multi-stage maceration is performed.

$$
\mathrm{q}=\mathrm{q}_{\mathrm{m}} \frac{\mathrm{K}_{\mathrm{L}} \cdot \mathrm{c}}{1+\mathrm{K}_{\mathrm{L}} \cdot \mathrm{c}}
$$

In recycling mode, Equation (15) is the mass balance for the storage vessel. V is the vessel's volume, $\dot{V}$ the flux, $c_{L}$ the concentration at the extraction column outlet and $c_{V}$ the concentration of the target component inside the vessel itself.

$$
\mathrm{V} \cdot \frac{\partial \mathrm{c}_{\mathrm{V}}}{\partial \mathrm{t}}=\dot{\mathrm{V}} \cdot\left(\mathrm{c}_{\mathrm{L}}-\mathrm{c}_{\mathrm{V}}\right)
$$

The equation is needed, because in recycling mode the concentration $\mathrm{c}_{\mathrm{L}}$ of the target component in the fluid entering the extraction column is not zero as is the case in the normal extraction mode. For batch extraction, Equation (15) is not taken into account because fresh solvent is applied [7].

\section{Results and Discussion}

Extraction from Artemisia annua L. is the first step to gain pure artemisinin on an industrial scale. In order to satisfy the demand, an optimized process is needed. Moreover, an extraction process without the use of organic solvents might be of interest. In this study, water is investigated as a substitute for common organic solvents. Furthermore, the aim of this study is to demonstrate how a model-based approach for the process design of solid-liquid extraction is performed and to highlight the benefits.

\subsection{Model-Based Optimization of the Conventional Solid-Liquid Extraction}

For the model-based process optimization of the solid-liquid extraction, model parameters such as the equilibrium or the overall amount of artemisinin have to be determined. The equilibrium is specific for each solvent, thus one has to perform a solvent selection prior to the parameter determination.

\subsubsection{Solvent Selection}

For an ideal process design the solvent choice is crucial. A well-chosen solvent should have a high capacity for the target molecule besides being cost effective, non-toxic and technically manageable. To find a suitable solvent, a screening was performed under ambient temperature. The results are presented in Figure 5. Practically, no artemisinin was extracted in pure water under normal conditions. By adding $10 \mathrm{~g} / \mathrm{L}$ of the surfactant Tween ${ }^{\circledR} 80\left(\right.$ Merck $^{\circledR}$, Darmstadt, Germany) a yield of approximately $12 \%$ compared to $n$-hexane as best solvent is reached. Therefore, water with Tween ${ }^{\circledR} 80$ can be used for extraction, but wouldn't be economically feasible due to additional costs and a high solvent viscosity. For the percolation in this study acetone is chosen as solvent. The capacity is about $80 \%$ compared to $n$-hexane but it is less toxic [35], according to the FDA's Guidance for Industry and the boiling point is about $10{ }^{\circ} \mathrm{C}$ lower. 


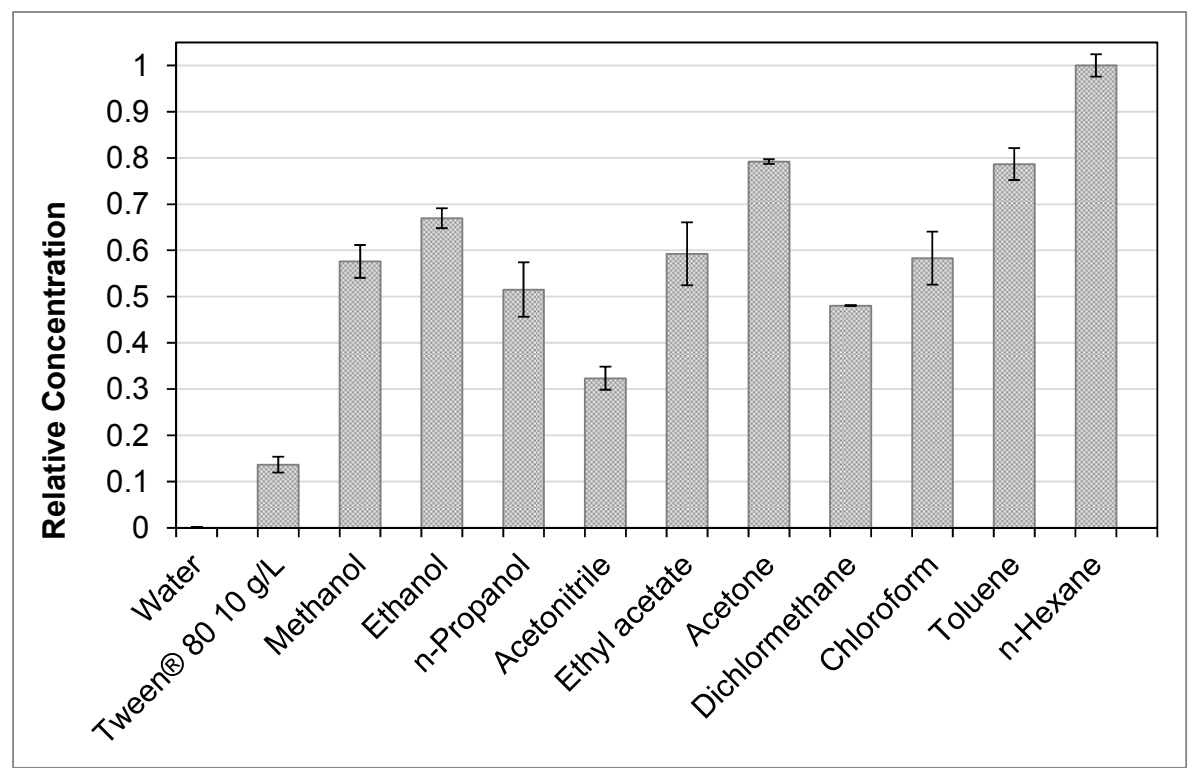

Figure 5. Solvent screening, solvents are arranged according to rising hydrophobicity.

It is interesting, that the solvent screening follows no systematic rule: acetone and toluene have nearly the same capacity for artemisinin but acetone is a significantly more polar solvent than toluene. In the field of the polar-protic alcohols, the solubility of artemisinin rises from methanol to ethanol, which might be traced to the lengthened aliphatic carbon chain. The solubility declines again when propanol is used. Apparently, the elongated carbon chain has a negative effect at that size.

\subsubsection{Overall Amount and Equilibrium}

The overall amount of artemisinin in the plant material was measured by exhaustive percolation with acetone. It is $0.395 \mathrm{wt} \% \pm 0.014 \mathrm{wt} \%$ related to dry mass. In the literature, values between $0.01 \mathrm{wt} \%-1.4 \mathrm{wt} \%$ are reported [12]. The equilibrium relation of artemisinin between the solid and the liquid phase is measured by multistep maceration experiments. The results are shown in Figure 6. The black line represents the overall amount.

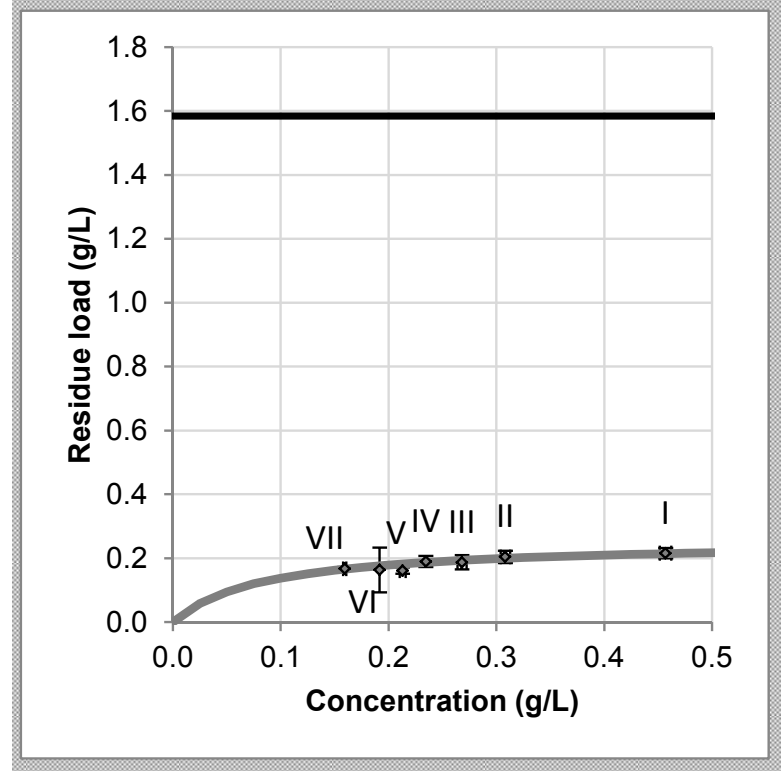

Figure 6. Equilibrium line of artemisinin from mugwort in acetone. 
Obviously, even few maceration steps lead to a high degree of leaching. The flat curve of the equilibrium line confirms acetone as suitable solvent. Otherwise, a low fluid concentration but a high residual loading of the plant material would have been observed. Because artemisinin is a product with high added value, a complete leaching is desirable. Therefore, percolation is chosen for this study $[3,4,6,29]$.

\subsection{Model-Based Optimization of the Pressurized Hot Water Extraction}

The first step in the process design for Pressurized Hot Water Extraction is to determine a suitable extraction temperature. According to the literature, artemisinin shows a relatively low stability towards higher temperatures [14]. This was also found in our temperature screening, shown in Figure 7. There, $2 \mathrm{~g}$ of ground mugwort were extracted at $1 \mathrm{~mL} / \mathrm{min}$, taking samples every $15 \mathrm{~min}$. The pressure was kept constant at $15 \mathrm{bar}$, to achieve a maximum of comparability. A temperature of $80^{\circ} \mathrm{C}$ leads to almost $100 \%$ yield after only $60 \mathrm{~min}$ of extraction. Higher temperatures such as $120{ }^{\circ} \mathrm{C}$ result in a significant loss of artemisinin probably due to decomposition, leading to a yield of only about $25 \%$. Thus, a temperature of $80^{\circ} \mathrm{C}$ is chosen for further investigations.

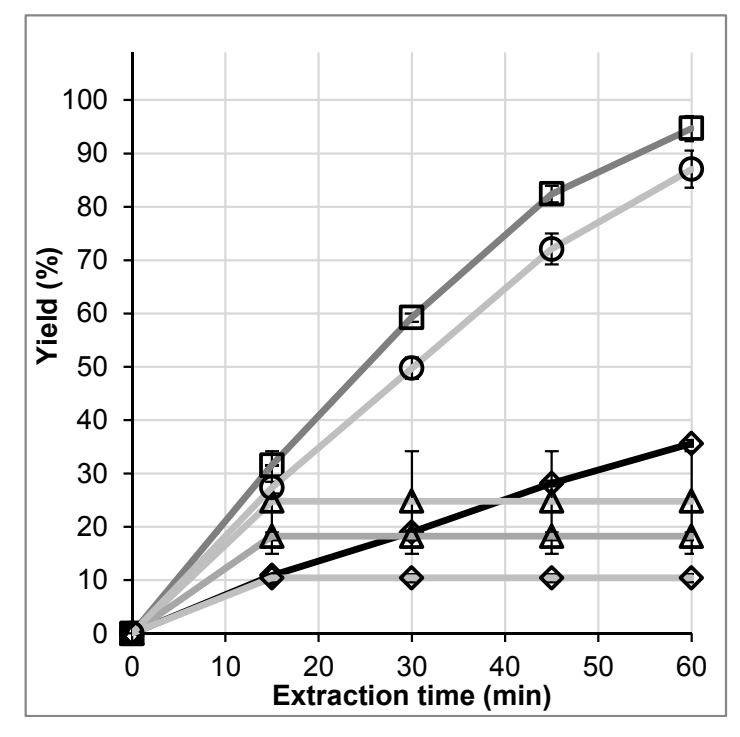

Figure 7. Extraction of artemisinin from annual mugwort using different temperatures.

The degradation kinetics of artemisinin is further investigated by recycling the extract according to the flowsheet of Figure 4 and our previous study [7]. The linearized curves for $80^{\circ} \mathrm{C}$ and $100{ }^{\circ} \mathrm{C}$ are shown in Figure 8 left. The data fits a linear model which allows the determination of the rate constant and the order of reaction, according to Equation (16).

$$
\log (\mathrm{r})=\log \left(\frac{\Delta \mathrm{c}}{\Delta \mathrm{t}}\right)=\log (\mathrm{k})+\mathrm{n} \cdot \log (\mathrm{c})
$$

Since the samples were taken from the storage vessel, only a pseudo-kinetics is measured. To transfer the data to the real conditions present in the extraction tube, Equation (17) is used.

$$
\mathrm{k}_{\mathrm{PFR}}=\mathrm{k}_{\mathrm{CSTR}} \cdot \frac{\tau_{\mathrm{CSTR}}}{\tau_{\mathrm{PFR}}}=\mathrm{k}_{\mathrm{CSTR}} \cdot \frac{\mathrm{V}_{\mathrm{CSTR}}}{\mathrm{V}_{\mathrm{PFR}}}
$$

This equation is derived by the Damköhler number (DaI) shown in (18) assuming physical similarity between the thermal degradation that occurs in the extraction tube and the measured pseudo-kinetics in the vessel [36].

$$
\mathrm{DaI}=\mathrm{k} \cdot \mathrm{c}_{1,0}^{\mathrm{m}-1} \cdot \mathrm{t}_{\mathrm{R}}
$$


For that, the Damköhler numbers of both reactions have the same value and the product $\mathrm{k} \cdot \mathrm{c}_{1,0}^{\mathrm{m}-1}$ can be replaced by the combined reaction rate coefficient $k_{C S T R}$ of the vessel and $k_{P F R}$ of the tube, respectively. The reaction time $t_{R}$ represents the residence times $\tau_{C S T R}$ and $\tau_{\text {PFR }}$ for each case. Because both regimes (extraction tube and the storage vessel) are switched in series, the residence times can be replaced by the individual volumes of the devices.

By linearization and conversion, the thermal degradation in the recycling mode can be simulated to verify the model parameter determination and the quality of data, as shown in Figure 8 right. At $60^{\circ} \mathrm{C}$ no degradation was observed but the productivity is not at an optimized level. Both, extraction at $80^{\circ} \mathrm{C}$ and $100^{\circ} \mathrm{C}$ in recycling mode can be simulated with the shown approach in a sufficient manner.
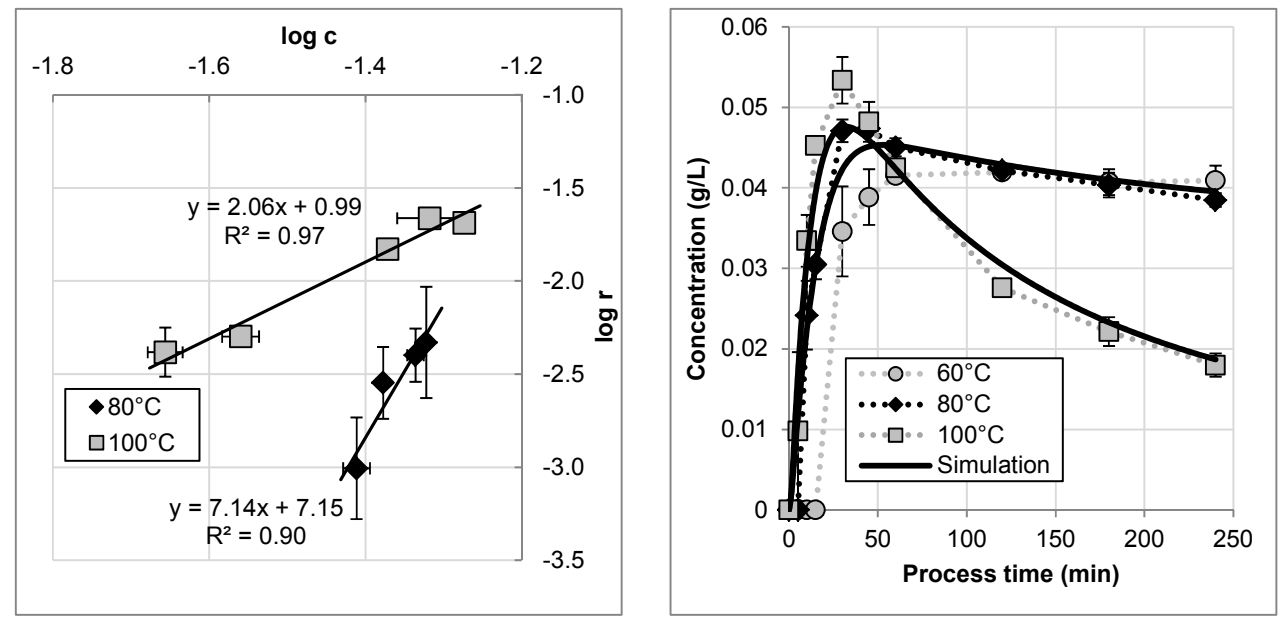

Figure 8. Left: linearization of the thermal decay of artemisinin; Right: simulation of the extraction in recycling mode for different temperatures (drawn line) and experimental data (points).

Due to thermal degradation, equilibrium measurements are not possible above $80{ }^{\circ} \mathrm{C}$, because the system will not reach a steady state. Moreover, the extraction process cannot be limited by equilibrium because of the permanent thermal decomposition of the target molecule. Therefore the equilibrium is neglected for the modeling of PHWE, which was found to be a reasonable assumption [7].

\subsection{Comparison of Solid-Liquid Extraction and PHWE}

The study indicates the great potential of using hot water for the extraction of artemisinin. A temperature of $80^{\circ} \mathrm{C}$ showed the best results with regard to productivity and thermal degradation. Moreover, artemisinin can easily be extracted with acetone as a typical organic solvent. The dielectric constant of acetone is 20.7 [27] whereas water has a value of 60.4 at $80^{\circ} \mathrm{C}$. This deviation does not allow a predictive choice of a suitable process temperature by matching the right dielectric constant of the organic solvent to be substituted with pressurized hot water. In the following part, some other differences and their technical consequences will be discussed in detail.

The differences between hot water extraction and conventional extraction (both in percolation mode) are shown in Figure 9 as extraction curves. On the left side, extraction kinetics for hot water extraction and conventional extraction are plotted for a high and a slow normalized flow rate over the extraction time. The flow is given in bed volumes per hour, which are calculated by Equation (19). $\dot{\mathrm{V}}_{\text {Solvent }}$ is the solvent flow $\mathrm{V}_{\text {Plant }}$ and the volume of the plant material as packed bed in the column.

$$
\frac{\mathrm{BV}}{\mathrm{h}}=\frac{\dot{\mathrm{V}}_{\text {Solvent }}}{\mathrm{V}_{\text {Plant }}}
$$

At high flow rates $(12 \mathrm{BV} / \mathrm{h}$ ), the hot water extraction reaches a yield of $95 \%$ (horizontal bar) after only 75 min of extraction time. A conventional percolation with a comparable flow rate reaches the 
same yield after $120 \mathrm{~min}$. At a lower flow rate $(1.4 \mathrm{BV} / \mathrm{h})$ the solvent based extraction reaches a yield of $95 \%$ after $400 \mathrm{~min}$. At the same time, the yield achieved in the hot water process has only a value of about $13 \%$. Because of the long residence time due to a low flow rate, the high thermal impact leads to a decay of artemisinin thus reducing the yield significantly.
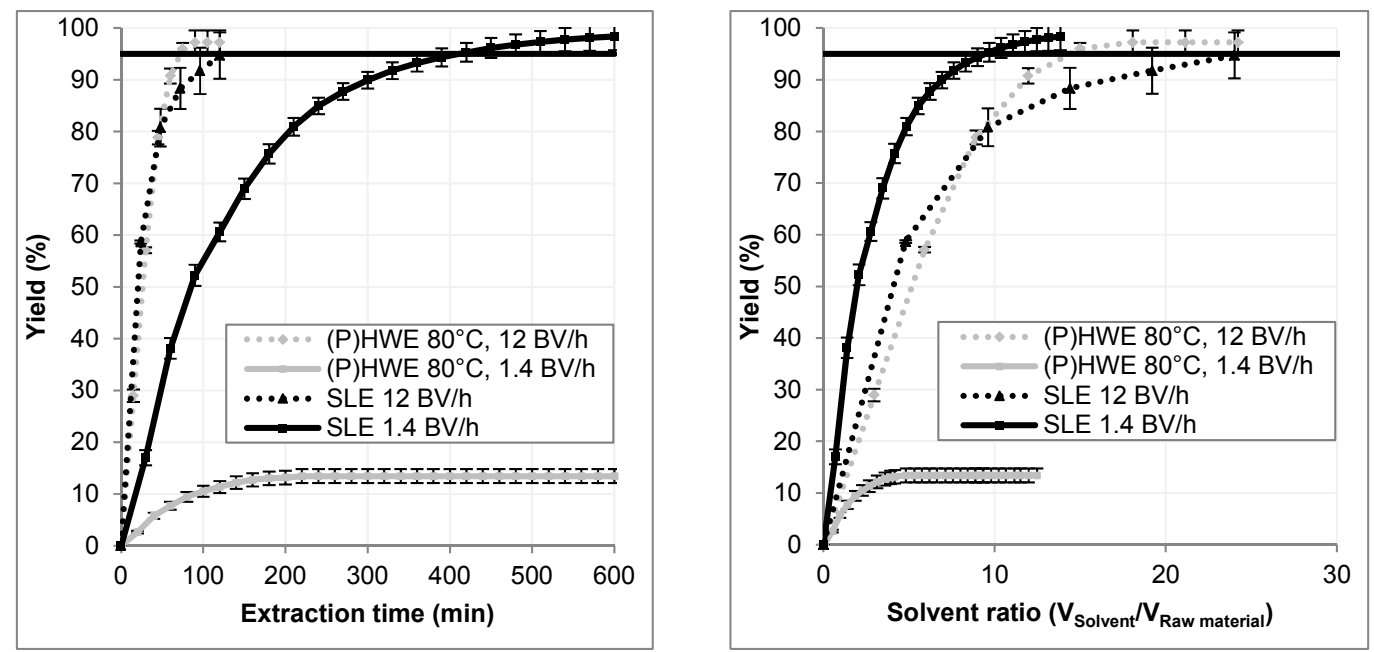

Figure 9. Comparison of the hot water extraction and the conventional extraction, horizontal bar is 95\% yield. Left: yield over extraction time, Right: yield over solvent ratio.

On the right side of Figure 9 the same extraction curves are plotted against the solvent ratio. The hot water extraction with high flow rates reaches a yield of $95 \%$ at a solvent ratio of 15 , in only $75 \mathrm{~min}$ of extraction time. This leads to a space-time yield of approximately $0.62 \mathrm{~g} / \mathrm{L} / \mathrm{h}$. The space-time yield is calculated by Equation (20).

$$
\mathrm{STY}=\frac{\mathrm{m}_{\text {Artemisinin }}}{\mathrm{t}_{\text {Extraction }} \cdot \mathrm{V}_{\text {Equipement }}}
$$

In the conventional percolation with a comparable flow rate, the same yield is reached after $120 \mathrm{~min}$ and a solvent ratio of $24(\mathrm{STY}=0.33 \mathrm{~g} / \mathrm{L} / \mathrm{h})$. This reflects the expectations, because on the one hand, the extraction process is not limited by the equilibrium as it was shown in Section 4.1.2, on the other hand, the artemisinin is located in the glandular trichomes at the surface of the leaves [16]. Thus, no diffusion limitation occurs and short residence times are sufficient for a complete leaching of the plant material. By applying only a low volume flow at the conventional percolation a yield of $95 \%$ is reached after $400 \mathrm{~min}$ at a solvent ratio of $10(\mathrm{STY}=0.1 \mathrm{~g} / \mathrm{L} / \mathrm{h})$. A comparable hot water extraction only reaches $13 \%$ yield due to thermal degradation.

Both techniques are suitable for the extraction of artemisinin. The solvent based process leads to a higher concentrated extract because of the lower solvent ratio by accepting a much longer process time and therefore a low productivity. The hot water process at those conditions will lead to the degradation of artemisinin, so for this extraction technique a high flow rate is needed. A temperature of $80{ }^{\circ} \mathrm{C}$ is by definition not a pressurized hot water extraction. For the process engineering implementation and design of this unit operation, this is not decisive. Moreover, within those conditions, the process can be realized without applying additional pressure.

This study showed a comparison of extreme process conditions (very high flowrate, very low flowrate). The operation parameters of an optimized process are somewhere in between these borders and an experimental optimization is rather time and resource intensive. With the shown approach of experimental model parameter determination in lab scale and the rigorous extraction model, these extrema can be simulated predictively, as shown in Figure 10. As a consequence, an optimization in-silico with such a physico-chemical process model is possible. 


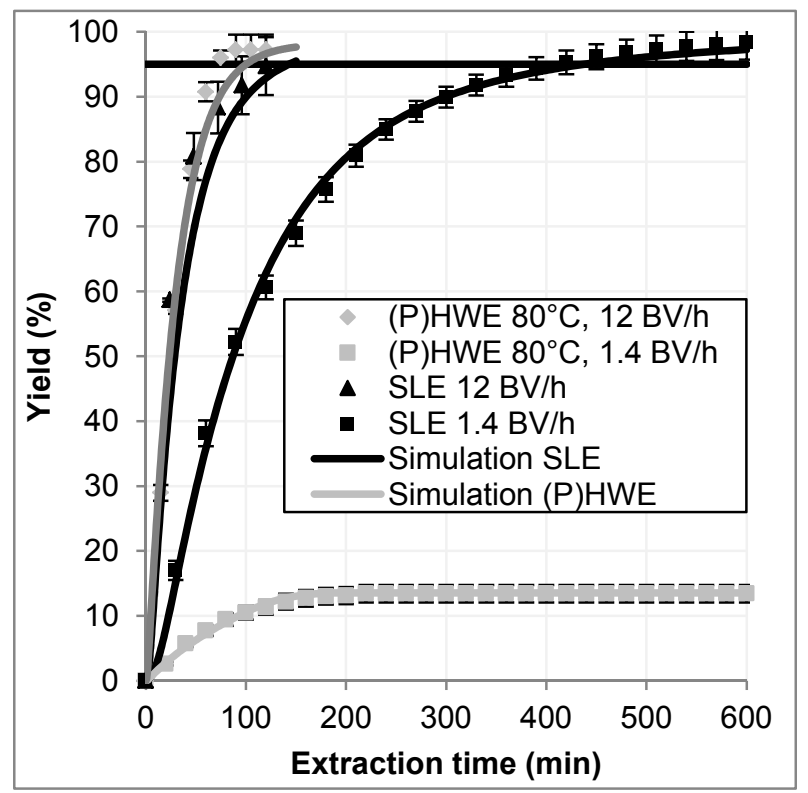

Figure 10. Experiments and simulation results of the conventional extraction and the hot water extraction.

\section{Conclusions}

The study showed a systematic and model based comparison of two different ways of extracting artemisinin from Artemisia annua L. Both, a percolation using acetone as solvent as well as an extraction with water at $80^{\circ} \mathrm{C}$, show high productivities and yields. The screening for a suitable organic solvent showed no obvious trend. This might be due to a highly complex side component spectrum that is extracted with every single solvent system. It is likely that these spectra influence the solubility of artemisinin over a wide range due to natural solubilizing effects, that have been observed for other extracts as well [6]. The combination of experimental model parameter determination and rigorous process model is a suitable way for predictive process simulation. The extraction can be optimized within a rather large field of possible parameter combinations. The thermal degradation was considered in the Pressurized Hot Water Extraction and showed how crucial a short residence time is for that specific process.

Acknowledgments: The authors thank the ITVP lab team, especially Frank Steinhäuser and Volker Strohmeyer, for their effort and support. We gratefully acknowledge the financial support obtained from the Deutsche Forschungsgemeinschaft (DFG) in Bonn, Germany (project Str 586/4-2).

Author Contributions: Maximilian Sixt conceived, designed and performed the experiment as well as wrote the paper. Jochen Strube is responsible for conception and supervision.

Conflicts of Interest: The authors declare no conflict of interest.

\section{Abbreviations}

A Parameter for Equation (1), $\mathrm{m}^{3} / \mathrm{kg}$

ap Specific surface area, $1 / \mathrm{m}$

B Parameter for Equation (1), $\mathrm{m}^{6} / \mathrm{kg}^{2}$

C Parameter for Equation (1), $\mathrm{m}^{6} / \mathrm{kg}^{2}$

$\mathrm{C}_{\mathrm{L}} \quad$ Concentration in the liquid phase, $\mathrm{kg} / \mathrm{m}^{3}$

$c_{\mathrm{P}} \quad$ Concentration in the porous particle, $\mathrm{kg} / \mathrm{m}^{3}$

$\mathrm{C}_{\mathrm{V}} \quad$ Concentration in a specific vessel, $\mathrm{kg} / \mathrm{m}^{3}$

D Parameter for Equation (1), $\mathrm{m}^{6} / \mathrm{kg}^{2}$

$\mathrm{D}_{\mathrm{ax}} \quad$ Axial dispersion coefficient, $\mathrm{m} / \mathrm{s}^{2}$ 
$\mathrm{D}_{\text {eff }} \quad$ Effective diffusion coefficient, $\mathrm{m}^{2} / \mathrm{s}$

E Parameter for Equation (1), $\mathrm{m}^{6} / \mathrm{kg}^{3}$

F Parameter for Equation (1), $\mathrm{m}^{6} / \mathrm{kg}^{3}$

G Parameter for Equation (1), $\mathrm{m}^{6} / \mathrm{kg}^{3}$

$\mathrm{H} \quad$ Parameter for Equation (1), $\mathrm{m}^{8} / \mathrm{kg}^{4}$

I Parameter for Equation (1), $\mathrm{m}^{8} / \mathrm{kg}^{4}$

K Parameter for Equation (1), $\mathrm{m}^{8} / \mathrm{kg}^{4}$

$\mathrm{k} \quad$ Reaction rate coefficient, Depending on order of reaction

$\mathrm{K}_{\mathrm{L}} \quad$ Equilibrium constant, $\mathrm{m}^{3} / \mathrm{kg}$

$\mathrm{k}_{\mathrm{EC}} \quad$ Rate coefficient in the extraction column, Depending on order of reaction

$\mathrm{k}_{\mathrm{f}} \quad$ Mass transport coefficient, $\mathrm{m} / \mathrm{s}$

$\mathrm{k}_{\mathrm{SV}} \quad$ Rate coefficient in the storage vessel, Depending on order of reaction

n Order of reaction, -

Pe Péclet number

q Loading, $\mathrm{kg} / \mathrm{m}^{3}$

$\mathrm{q}_{\max } \quad$ Maximum Loading, $\mathrm{kg} / \mathrm{m}^{3}$

Re Reynolds number

$\mathrm{r} \quad$ Radius, $\mathrm{m}$

Sc Schmidt number

Sh Sherwood number

$\mathrm{T}$ Temperature, $\mathrm{K}$

$\mathrm{t} \quad$ Time, $\mathrm{s}$

$\mathrm{T}^{*} \quad$ Normalized temperature for Equation (1), -

$\mathrm{u}_{\mathrm{z}} \quad$ Superficial velocity, $\mathrm{m} / \mathrm{s}$

$\mathrm{V} \quad$ Volume, $\mathrm{m}^{3}$

$\dot{\mathrm{V}} \quad$ Volume flow, $\mathrm{m}^{3} / \mathrm{s}$

$\mathrm{z} \quad$ Coordinate in axial direction, $\mathrm{m}$

$\varepsilon \quad$ Dielectric constant, -

$\varepsilon \quad$ Voids fraction, -

$\varrho \quad$ Density, $\mathrm{kg} / \mathrm{m}^{3}$

$\varrho^{*} \quad$ Normalized density for Equation (1), -

$\tau_{\mathrm{EC}} \quad$ Residence time in the extraction vessel, $\mathrm{s}$

$\tau_{\mathrm{SV}} \quad$ Residence time in the storage vessel, $\mathrm{s}$

DPF Distributed plug flow

ELSD Evaporation Light Scattering Detector

HPLC High performance liquid chromatography

i.d. Inner diameter

PHWE Pressurized hot water extraction

PTFE Polytetrafluoroethylene

STY Space-time yield

\section{References}

1. Kassing, M.; Jenelten, U.; Schenk, J.; Hänsch, R.; Strube, J. Combination of Rigorous and Statistical Modeling for Process Development of Plant-Based Extractions Based on Mass Balances and Biological Aspects. Chem. Eng. Technol. 2012, 35, 109-132. [CrossRef]

2. Ditz, R.; Gerard, D.; Hagels, H.; Igl, N.; Schäffler, M.; Schulz, H.; Stürtz, M.; Tegtmeier, M.; Treutwein, J.; Strube, J.; et al. Phytoextracts—Proposal towards a New Comprehensive Research Focus; DECHEMA: Frankfurt, Germany, 2017.

3. Both, S. Systematische Verfahrensentwicklung für Pflanzlich Basierte Produkte im Regulatorischen Umfeld; Shaker: Aachen, Germany, 2015.

4. $\quad$ Koudous, I. Stoffdatenbasierte Verfahrensentwicklung zur Isolierung von Wertstoffen aus Pflanzenextrakten, 1st ed.; Shaker: Herzogenrath, Germany, 2017. 
5. Koudous, I.; Both, S.; Gudi, G.; Schulz, H.; Strube, J. Process design based on physicochemical properties for the example of obtaining valuable products from plant-based extracts. C. R. Chim. 2014, 17, 218-231. [CrossRef]

6. Sixt, M.; Koudous, I.; Strube, J. Process design for integration of extraction, purification and formulation with alternative solvent concepts. C. R. Chim. 2016, 19, 733-748. [CrossRef]

7. Sixt, M.; Strube, J. Pressurized hot water extraction of 10 -deacetylbaccatin III from yew for industrial application. Resour. Effic. Technol. 2017, 3, 177-186. [CrossRef]

8. Plaza, M.; Turner, C. Pressurized hot water extraction of bioactives. Trends Anal. Chem. 2015, 71, 39-54. [CrossRef]

9. Teo, C.C.; Tan, S.N.; Yong, J.W.H.; Hew, C.S.; Ong, E.S. Pressurized hot water extraction (PHWE). J. Chromatogr. A 2010, 1217, 2484-2494. [CrossRef] [PubMed]

10. Lightburn, B.; Mazza, G. An Introduction to the Green, Clean and Economical Mazza Extraction Technology. In Proceedings of the International Congress on Green Extraction of Natural Products (GENP 2016), Turin, Italy, 31 May-1 June 2016.

11. Mazza, G.; Pronyk, C. Pressurized Low Polarity Water Extraction Apparatus and Methods of Use. U.S. Patent 9,084,948, 21 July 2015.

12. Christen, P.; Veuthey, J. New Trends in Extraction, Identification and Quantification of Artemisinin and its Derivatives. Curr. Med. Chem. 2001, 8, 1827-1839. [CrossRef] [PubMed]

13. Krishna, S.; Bustamante, L.; Haynes, R.K.; Staines, H.M. Artemisinins: Their growing importance in medicine. Trends Pharmacol. Sci. 2008, 29, 520-527. [CrossRef] [PubMed]

14. Tu, Y. From Artemisia annua L. to Artemisinins. The Discovery and Development of Artemisinins and Antimalarial Agents; Elsevier Science: San Diego, CA, USA, 2017.

15. Liu, C.-Z.; Zhou, H.-Y.; Zhao, Y. An effective method for fast determination of artemisinin in Artemisia annua L. by high performance liquid chromatography with evaporative light scattering detection. Anal. Chim. Acta 2007, 581, 298-302. [CrossRef] [PubMed]

16. Duke, M.V.; Paul, R.N.; Elsohly, H.N.; Sturtz, G.; Duke, S.O. Localization of Artemisinin and Artemisitene in Foliar Tissues of Glanded and Glandless Biotypes of Artemisia annua L. Int. J. Plant Sci. 1994, 155, 365-372. [CrossRef]

17. Nobel Foundation. The Nobel Prize in Physiology or Medicine 2015; Press Release: Stockholm, Sweden, 2015.

18. Brown, G. Artemisinin and a new generation of antimalarial drugs. Educ. Chem. 2006, 43, 97-99.

19. Kumar, S.; Gupta Kumar, S.; Singh, D. Process for Isolating Artemisinin from Artemisia Annua. U.S. Patent 6,685,972, 3 February 2004.

20. Hao, J.-Y.; Han, W.; Huang, S.-D.; Xue, B.-Y.; Deng, X. Microwave-assisted extraction of artemisinin from Artemisia annua L. Sep. Purif. Technol. 2002, 28, 191-196. [CrossRef]

21. Briars, R.; Paniwnyk, L. Effect of ultrasound on the extraction of artemisinin from Artemisia annua. Ind. Crops Prod. 2013, 42, 595-600. [CrossRef]

22. Quispe-Condori, S.; Sánchez, D.; Foglio, M.A.; Rosa, P.T.; Zetzl, C.; Brunner, G.; Meireles, M.A.A. Global yield isotherms and kinetic of artemisinin extraction from Artemisia annua L. leaves using supercritical carbon dioxide. J. Supercrit. Fluids 2005, 36, 40-48. [CrossRef]

23. Kohler, M.; Haerdi, W.; Christen, P.; Veuthey, J.-L. Extraction of artemisinin and artemisinic acid from Artemisia annua L. using supercritical carbon dioxide. J. Chromatogr. A 1997, 785, 353-360. [CrossRef]

24. Sovová, $\mathrm{H}$. Rate of the vegetable oil extraction with supercritical $\mathrm{CO}_{2}-\mathrm{I}$. Modelling of extraction curves. Chem. Eng. Sci. 1994, 49, 409-414. [CrossRef]

25. Martínez, J.; Monteiro, A.R.; Rosa, P.T.V.; Marques, M.O.M.; Meireles, M.A.A. Multicomponent Model to Describe Extraction of Ginger Oleoresin with Supercritical Carbon Dioxide. Ind. Eng. Chem. Res. 2003, 42, 1057-1063. [CrossRef]

26. Lapkin, A.A.; Plucinski, P.K.; Cutler, M. Comparative assessment of technologies for extraction of artemisinin. J. Nat. Prod. 2006, 69, 1653-1664. [CrossRef] [PubMed]

27. Dalton, L. Dielectric Chart. Available online: http://depts.washington.edu/eooptic/linkfiles/dielectric_ chart\%5B1\%5D.pdf (accessed on 12 October 2017).

28. Grigull, U. Dielektrizitätskonstante und Ionenprodukt von Wasser und Wasserdampf. Brennst. Wärme Kraft 1983, 35, 253-258.

29. Kaßing, M. Process Development for Plant-Based Extract Production; Shaker: Aachen, Germany, 2012. 
30. Lapkin, A.A.; Walker, A.; Sullivan, N.; Khambay, B.; Mlambo, B.; Chemat, S. Development of HPLC analytical protocol for artemisinin quantification in plant materials and extracts. J. Pharm. Biomed. Anal. 2009, 49, 908-915. [CrossRef] [PubMed]

31. Both, S.; Koudous, I.; Jenelten, U.; Strube, J. Model-based equipment-design for plant-based extraction processes-considering botanic and thermodynamic aspects. C. R. Chim. 2014, 17, 187-196. [CrossRef]

32. Schmidt-Traub, H. Preparative Chromatography, 2nd ed.; Wiley-VCH Verlag: Weinheim, Germany, 2013.

33. Altenhöner, U.; Meurer, M.; Strube, J.; Schmidt-Traub, H. Parameter estimation for the simulation of liquid chromatography. J. Chromatogr. A 1997, 769, 59-69. [CrossRef]

34. Strube, J.; Altenhöner, U.; Meurer, M.; Schmidt-Traub, H.; Schulte, M. Dynamic simulation of simulated moving-bed chromatographic processes for the optimization of chiral separations. J. Chromatogr. A 1997, 769, 81-92. [CrossRef]

35. Food and Drug Administration (FDA). Guidance for Industry: Q3C_-Tables and List; FDA: Rockville, MD, USA, 2017.

36. Levenspiel, O. Chemical Reaction Engineering, 3rd ed.; Wiley: New York, NY, USA, 1999.

(C) 2017 by the authors. Licensee MDPI, Basel, Switzerland. This article is an open access article distributed under the terms and conditions of the Creative Commons Attribution (CC BY) license (http://creativecommons.org/licenses/by/4.0/). 